\title{
Formação histórica e trajetórias migratórias: o caso de Imperatriz-MA
}

Edgar Oliveira Santos

Universidade Estadual da Região Tocantina do Maranhão (UEMASUL)

Edney Loiola

Universidade Estadual da Região Tocantina do Maranhão (UEMASUL)

Sônia Oliveira Santos

Universidade Cruzeiro do Sul (UNICSUL)

Rafael de Oliveira Araújo

Universidade Estadual do Maranhão (UEMA)

Antônio Pereira Lucena

Universidade Estadual da Região Tocantina do Maranhão (UEMASUL)

Recebido: 28/09/2018 Versão revisada (entregue): 21/05/2019 Aprovado: 01/06/2019

\begin{abstract}
Resumo
O presente artigo é resultado de um estudo sobre dinâmicas regionais de desenvolvimento, propiciando a formação de redes migratórias e, consequentemente, a própria configuração das trajetórias migratórias observadas num determinado espaço/tempo. O espaço central de análise é o município de Imperatriz, localizado no sudoeste do estado do Maranhão, que possui uma formação histórica que pode ser compreendida a partir de ciclos de desenvolvimento econômico, influenciando os fluxos migratórios responsáveis pelo povoamento do município a partir da década de 1960. A abordagem em torno dessa construção espacial fundamenta-se no método materialista histórico, com qual se enfatizaram a historicidade e as contradições presentes nas formas como a dinâmica de desenvolvimento do município de Imperatriz condicionou os fluxos migratórios que o povoaram a partir da década de 1960.
\end{abstract}

Palavras-chave | desenvolvimento regional; formação histórica; Imperatriz; fluxos migratórios.

Código JEL | J61 O15 R23

\section{Historical formation and migratory trajectories: the case of Imperatriz-MA}

\begin{abstract}
The present article is the result of a study carried out with the purpose of analyzing regional development dynamics, promoting the formation of migratory networks and consequently, the configuration of migratory trajectories observed in a given space/time. The central area of
\end{abstract}


analysis is the municipality of Imperatriz, located in the South-west of Maranhão. This Brazilian state has a historical formation constituted by cycles of economic development, influencing the migratory flows responsible for the settlement of the municipality from the 1960s. This spatial construction is based on the historical materialist method, which the historicity and the contradictions present in the spatial forms were examined. In addition, it addresses how the development dynamics in the municipality of Imperatriz conditioned the migratory flows that populated it from the 1960s.

Keywords | Historical formation; Imperatriz; migratory flows; regional development.

JEL-Code | J61 O15 R23

\section{Formación histórica y trayectorias migratorias: el caso de Imperatriz-MA}

\section{Resumen}

El presente artículo es el resultado de un estudio sobre dinámicas regionales de desarrollo, propiciando la formación de redes migratorias y, consecuentemente, la propia configuración de las trayectorias migratorias observadas en un determinado espacio / tiempo. El espacio central de análisis es el municipio de Imperatriz, ubicado en el suroeste del estado de Maranhão, que posee una formación histórica constituida por ciclos de desarrollo económico, influenciando los flujos migratorios responsables por el poblamiento del municipio a partir de la década de 1960. El abordaje en torno a esta construcción espacial se fundamenta en el método materialista histórico, con el que se enfatizaron la historicidad y las contradicciones presentes en las formas como la dinámica de desarrollo del municipio de Imperatriz condicionó los flujos migratorios que lo poblaron a partir de la década de 1960.

Palabras-clave | desarrollo regional; formación histórica; Imperatriz; flujos migratorios.

Código JEL | J61 O15 R23

\section{Introdução}

O presente artigo é resultado de um trabalho investigativo sobre migrações internas, com o objetivo de analisar dinâmicas regionais de desenvolvimento configuradas no contexto de redes e trajetórias migratórias estruturadas num determinado espaço/tempo. O espaço de estudo é a região sul do estado do Maranhão, focalizando o município de Imperatriz por meio da sua formação histórica, constituída por ciclos de desenvolvimento econômico no período de 1960 a 1980.

O estudo das migrações internas ocupa um auspicioso espaço de pesquisa, que promove novas discussões acadêmicas, buscando responder aos questionamentos teóricos confrontados com os diversificados movimentos populacionais, 
sobretudo nas escalas nacionais, regionais e locais. Esses debates são originados com as constantes mudanças da sociedade, em resposta às recentes configurações assumidas pelo sistema de produção capitalista.

Essas mudanças decorrentes das diferenças regionais, originadas pelo processo de industrialização nos moldes capitalistas, criaram novos fluxos migratórios numa perspectiva distinta, em alguns aspectos, dos movimentos migratórios do Nordeste para o Sudeste do país. Nesse novo cenário de mudanças nos deslocamentos populacionais, insere-se o município de Imperatriz. A cidade, nesta abordagem, é considerada referência para o estudo da relação entre as dinâmicas regionais de desenvolvimento e fluxos migratórios na região Sudoeste do Maranhão. A formação histórica de Imperatriz, no período compreendido entre 1960 e 1980, foi constituída por "ciclos de desenvolvimento econômico". Nesse sentido, atenta-se para os fluxos migratórios que, condicionados por esses diferentes "ciclos de desenvolvimento econômico", contribuíram na dinâmica populacional do município de Imperatriz a partir da década de 1960.

Especificamente sob o ponto de vista da dinâmica populacional, com base nos dados dos censos demográficos realizados entre 1960 e 1980, é possível perceber um surto de crescimento no município de Imperatriz. Em 1960 Imperatriz possuía uma população total de 39.169, em 1970 atinge 80.722 habitantes e em 1980 a população total do município alcançou 220.079 habitantes (IBGE, CENSOS 1960, 1970, 1980).

A magnitude apontada pelos dados populacionais de Imperatriz, no período entre 1960 e 1980, induz a acreditar que a maior parte da ocupação espacial daquele município ocorreu durante as décadas de 1970 e 1980. Esses dados levantam uma série de indagações, principalmente sobre a forma como se constituíram os fluxos migratórios a partir dos ciclos econômicos responsáveis por essa ocupação populacional, bem como os fatores que contribuíram para incentivar a migração dos lugares de origem para Imperatriz. A Figura 1 mostra a divisão geopolítica dos municípios da região sul do Maranhão. 
Figura 1 - Mapa de localização da área de estudo: região sul do Maranhão

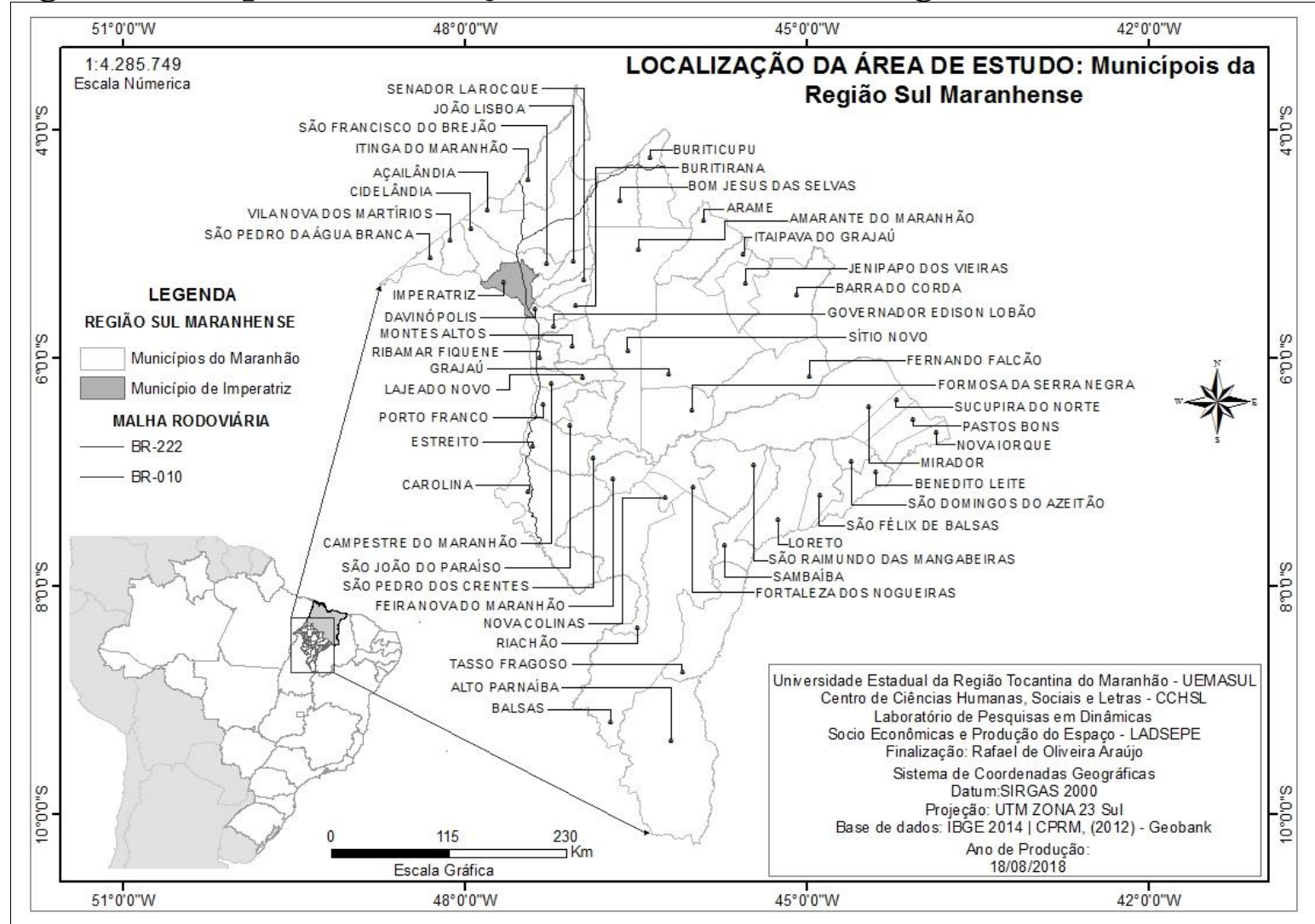

Fonte: Mapa elaborado utilizando o software QGISDEKSTOP/1.8.0, (2018).

É importante observar que as migrações não são fenômenos estritamente demográficos. As trajetórias migratórias são fluxos migratórios caracterizados pela sua importância social, na medida em que são originadas a partir dos desequilíbrios regionais que se modificam em função dos desequilíbrios regionais (BRITO, 2002). Nesse mesmo enfoque, o conceito de redes migratórias compreende diferentes autores como Baeninger (2012), Cano (1996) e Duhram (1973), resultando em diferentes perspectivas de análise das dinâmicas migratórias.

Não se trata de enfatizar as motivações individuais dos migrantes, que permitem compreender por que os mesmos decidem migrar para determinados lugares. Sequer de uma análise centrada nas relações interpessoais, entre indivíduos ou entre indivíduos e instituições (famílias, igrejas, sindicatos etc.) que, afinal, condicionam as decisões dos migrantes. Ainda que essas questões tenham importância, o que se pretende analisar são as complexas relações que se estabelecem, não somente entre os agentes e as instituições, mas também, entre os diferentes espaços, compondo redes e, consequentemente, as trajetórias migratórias.

Há a compreensão de que as redes migratórias configuram relações sociais, edificadas a partir das influências de um migrante em seu retorno (SOARES, 2002). 
Assim como há a compreensão de que as redes migratórias são estabelecidas por um conjunto de expectativas mútuas, que geram comportamentos determinados e consolidam relações entre pessoas, bens e informações. Conectando territorialmente migrantes a não migrantes e as instituições; instituições a instituições e as comunidades de origem aos lugares definidos como "locais de destino". Nesse sentido, entende-se também que as migrações apresentam o poder de construir vínculos duradouros entre pessoas e lugares (BRAGA, 2004; FAZITO, 2010).

A migração deriva das relações entre as trajetórias, que são orientadas a partir de redes circunscritas ao âmbito familiar. Contudo, essas redes podem ser ampliadas, ligando-se a outras (TRUZZI, 2006), formando fluxos migratórios que interferem espacialmente no lugar de destino com possibilidades transformadoras.

Analisar o processo migratório em Imperatriz, considerando o seu povoamento numa perspectiva histórica, é construir uma trajetória em torno de um conjunto diversificado de circunstâncias, buscando elucidar os fatos registrados ao longo da formação histórica do município. O município de Imperatriz ficou, pelo menos até a metade do século XX, isolado da maior parte do estado do Maranhão e, mesmo, do país. "Ressurgiu" na segunda metade do século XX, mais especificamente a partir da década de 1960, com um rápido povoamento. Seu processo de ocupação espacial, focado em correntes migratórias, é difuso quanto aos fatores de influência para migração na origem, migração e permanência no destino. As variáveis "distância", "tecnologia" e "condições econômicas", consideradas por Ravenstein (1980) como fatores de influência nas migrações, não se apresentavam acessíveis em face das condições de isolamento de Imperatriz no período de estudo $(1960$ - 1980).

Este trabalho fundamenta-se pelo materialismo histórico como método de abordagem considerando que esse, em princípio, indica o pensamento filosófico que tem a matéria como a primeira substância e a última de qualquer ser, coisa ou fenômeno do universo. Trata-se de uma concepção de mundo segundo a qual a realidade é a matéria em movimento e as suas condições materiais concretas de desenvolvimento são fundamentais para a explicação de fenômenos que se apresentam numa investigação, inclusive os mentais, sociais e históricos (ALVES, 2010).

Marx (2006) constrói o materialismo histórico em oposição à dialética idealista de Hegel. O idealismo, diferente do materialismo, procura explicar o mundo pelas ideias, pelos conceitos ou pelo espírito. É a doutrina que afirma ser a consciência, a ideia, aquilo que determina o mundo e a existência do ser e das coisas. Enquanto a visão marxista parte de uma abordagem ontológica do conhecimento da realidade que se fundamenta no conhecimento de cada modo do ser, bem como de suas interações com outros seres. 
Considerando a abordagem para explicar aspectos relacionados à construção de uma estrutura e superestrutura segundo a concepção de Marx (2006), utiliza-se ainda as técnicas de entrevistas visando qualificar a coleta de dados empíricos extraídos do Censo Demográfico e de registros bibliográficos.

Acreditando na consistência de análise orientada por essa estrutura metodológica, o presente artigo é composto por cinco partes, iniciando por esta introdução. A segunda aborda discussões teóricas, na perspectiva das migrações internas. A terceira busca por meio de dados estatísticos uma maior aproximação com as origens do desenvolvimento da região Nordeste. A quarta analisa os ciclos de desenvolvimento e migrações no contexto da formação histórica de Imperatriz (1960-1980). A última parte é representada pelas considerações finais.

\section{Abordagens teóricas das migrações internas}

A sensível tarefa de tentar compreender as migrações internas é inerente ao entendimento dos inúmeros aspectos que integram uma sociedade, que tem na sua função de produção uma mobilidade espacial da população, com poderes para interagir socialmente e economicamente na construção e reconstrução do espaço habitado. Diante desse entendimento, busca-se caminhos para uma melhor aproximação compreensível no âmbito dessas migrações refletidas a partir do final do século XX.

As abordagens teóricas sobre migração durante muito tempo foram divididas entre as correntes funcionalista e estruturalista representada por autores como Lee (1980), Singer (1980). A primeira acredita que o indivíduo decide migrar após analisar racionalmente a relação custo-benefício com o processo migratório e, nessa concepção, a migração seria a mudança permanente ou não de residência, independente da distância do deslocamento, da condição voluntária ou involuntária e se é externa ou interna.

Com relação ao destino, Singer (1980) afirma que esses fatores da estagnação como insuficiência física da área produtiva conduziriam a uma maior dificuldade de inserção do migrante no mercado de trabalho. A migração é um fenômeno que se apresenta de forma intrínseca na constituição produtiva da sociedade, acarretando impactos tanto na origem quanto no destino. A ótica que direciona as análises desses dois autores diferencia-se segundo os interesses. Para o primeiro, a questão sociológica seria a abordagem principal, enquanto ao segundo, o viés econômico como no destino.

As teorias migratórias foram, de modo geral, influenciadas pela industrialização e pelo desenvolvimento econômico sendo fundamentadas no enfoque estruturalista e na teoria da modernização. Entretanto, atualmente, num ambiente pósindustrial, as ligações entre os movimentos são dadas sobre a base de redes 
interpessoais, comunicações articuladas, retroalimentação e interdependência de sistemas numa economia global (SIMMONS, 1991; OLIVEIRA, 2011).

Simmons (1991) sustenta que as migrações estariam definidas em termos tão amplos que poderiam estar incluindo todos os níveis diferentes de fenômenos e, possivelmente, nenhuma explicação daria conta de contemplar todos. Assim, ele assevera, a solução seria o uso de tipologias descritivas de modo a isolar o fenômeno e interpretá-lo no marco de análise, de forma que se ajuste a cada caso específico (SIMMONS, 1991; OLIVEIRA, 2011).

A discussão sobre migração e desenvolvimento tem oscilado desde o otimismo desenvolvimentista nas décadas de 1950 e 1960 até pontos de vista pessimistas neomarxista nos anos 1970 e 1980, em direção a visões mais otimistas nas décadas de 1990 e 2000. Contudo, as evidências empíricas que apontam para a heterogeneidade dos impactos migratórios têm desafiado essas visões. Os pontos de vista são, em grande parte, orientados ideologicamente e desviam a atenção das restrições estruturais e do papel vital dos estados na formação de condições favoráveis para que ocorram impactos positivos na migração (DE HASS, 2010).

Os estudos que tentam incluir migração na política econômica são associados com a suposição de que a emigração pode contribuir positivamente para o desenvolvimento do país de origem dos imigrantes. Porém, essa análise otimista, que vem dominando a discussão econômica nos últimos 20 anos, é questionada pelo enfoque pessimista com a pressuposição de que emigram os indivíduos mais qualificados. Nesse caso, a migração é um fenômeno associado a danos para os estados emissores, contribuindo para o agravamento da pobreza (DE HASS, 2010).

As razões que originam um determinado deslocamento podem estar associadas às transformações estruturais nas sociedades. No entanto, a continuidade da migração provavelmente está mais relacionada a laços estabelecidos entre locais de origem e destino, que conferem estabilidade aos fluxos contínuos entre duas ou mais localidades. Desse modo, as redes sociais não são elaboradas no movimento migratório, mas transformadas por ele na medida em que se reforçam as conexões existentes entre o migrante e outros atores da sociedade (SOARES, 2002).

As redes sociais podem ser compreendidas, então, como o conjunto de pessoas, organizações ou instituições sociais conectadas por algum tipo de relação, podendo, inclusive, sobreporem-se inúmeras vezes dentro de um sistema de relações. As redes migratórias seriam, então, uma espécie de rede social, precedida por outras redes que se adaptam ao objetivo de migrar, como as relações de parentesco, amizade, trabalho etc. (SOARES, 2002; FAZITO, 2002).

Desse modo, os fluxos migratórios internos na rede urbana brasileira podem ser compreendidos, segundo a perspectiva de análise, na qual as localidades são os atores conectados por laços gerados pela migração, formando uma rede social que contém vários níveis de relações estabelecidas pelos imigrantes. 
Essa concepção permite trabalhar sobre alguns princípios básicos, como assinala Soares (2002): a) os laços relacionais ou conexões entre atores são canais de transferência de recursos e b) os modelos de rede conceituam estruturas (sociais, econômicas, políticas, demográficas etc.) como padrões duráveis de relações entre atores. Essa forma de tratamento das redes migratórias, ao evidenciar os laços entre imigrantes, pode contribuir para os estudos de redes urbanas, já que as redes sociais presentes na migração integram o conjunto das interações espaciais que compõem os sistemas de cidades. Evidentemente, quanto mais relações entre centros urbanos forem descobertas, mais consistentes tornam-se os modelos teóricos explicativos para as redes de localidades centrais (SOARES, 2002).

As redes presentes nas localidades de origem e destino podem colocar o imigrante mais rapidamente no mercado de trabalho, principalmente ao se considerar que as redes sociais podem selecionar melhores níveis de qualificação. Assim, a compreensão da contribuição dos imigrantes para a evolução da rede urbana brasileira pode ser enriquecida na consideração dos padrões relacionais expressos nas redes sociais da migração (MATOS; BRAGA, 2004).

De acordo com Baeninger (2012), o panorama migratório deste século apresenta dois grandes conjuntos redistributivos nacionais, sendo um caracterizado pela variação migratória metropolitana, marcado pelos significativos volumes de migrantes de retorno interestaduais saindo do Sudeste em direção ao Nordeste. O outro refere-se à interiorização migratória, com trajetórias de curtas distâncias, envolvendo aglomerações urbanas e espaços não-metropolitanos nos estados e nas regiões.

Os processos migratórios tornaram-se reversíveis, adquirindo significado distinto, quando se contempla dinâmicas urbano-regionais específicas. As migrações redefinem seus polos, configurando mais áreas de retenção da migração do que áreas com uma tendência polarizadora de longa permanência. Essas modificações são consequências de inúmeras transformações ocorridas no cenário econômico internacional e nacional que promoveram efeitos nos campos político e econômico (BAENINGER, 2012).

Essa nova dinâmica pode ser entendida observando o cenário atual das migrações no país, com destaque para a região Nordeste. Com as tendências que se delineiam nos últimos 20 anos, essa região continuou o decréscimo em seus saldos migratórios negativos, o que indica a força da migração de retorno na composição de sua imigração.

Entretanto, a dinâmica da redistribuição da população no espaço vincula-se, historicamente, às transformações estruturais pelas quais a sociedade brasileira passou, tendo como elementos básicos os processos migratórios e de urbanização (FARIA, 1991). Nessas transformações econômicas estruturaram-se e redefiniramse os movimentos migratórios de acordo com os locais da produção de riqueza (MATOS; BAENINGER, 2001), como se observa, historicamente, as articulações 
da etapa econômica e a migração até pelo menos, a última década do século XX (BAENINGER, 2012).

$\mathrm{Na}$ noção de redes sociais estaria o condicionante da migração, sobretudo pelo papel facilitador da inserção no mercado de trabalho e na sociedade do lugar de destino. Contudo, os estudos sobre redes ainda são insuficientes para aglutinar as discussões teóricas que tipificam motivos, intensidades, permanência e formas de interferência das migrações internas (RAMELLA, 1995; OLIVEIRA, 2011).

No estudo da teoria das redes migratórias observa-se que na função delas encontra-se a formatação de um diagnóstico, o qual incide sobre o nível de desenvolvimento regional do destino pretendido. Nesse caso, a migração pode ser interpretada como uma resposta às expectativas desse destino, bem como às frustrações na origem. Nos diversos aspectos que influenciam essas expectativas estão incluídos os padrões de vida regionais, principalmente, o bem-estar individual que está relacionado às condições médias de infraestrutura domiciliar de cada localidade (SOUZA, 1973; LIMA, 2000).

A teoria das redes é considerada essencial na explicação dos motivos de a migração não ocorrer de modo uniforme no território nacional, considerando que existem determinadas regiões de alta concentração de migrantes ligados a lugares específicos por meio das redes migratórias (FUSCO, 2005).

As expectativas presentes na decisão de migrar envolvendo a busca pela melhoria de vida parecem constituir o cerne das discussões nas construções teóricas da migração. Essas discussões orientam o entendimento de uma perspectiva das novas migrações internas, uma vez que, no início deste século, elas tornaram-se ainda mais complexas. Portanto, o novo olhar para os processos migratórios conduz à substituição de conceitos, observando que, duas dimensões estão particularmente presentes na redefinição desses processos. Em primeiro lugar, a reversibilidade dos diferentes fluxos migratórios, em especial as oscilações nos volumes de emigração e imigração e suas novas modalidades. Em segundo, a menor permanência das condições da migração para a caracterização das áreas (BAENINGER. 2012).

\section{Dinâmicas de desenvolvimento na região nordeste}

Com base nas discussões erigidas neste artigo até o momento, considera-se necessário compartilhar das teorias de Furtado (1984, 1989, 2008), Oliveira (1981), Oliveira, Garcia e Stern (1983) e Carvalho (2008) a propósito, sobretudo, do desenvolvimento desigual. Intenciona-se construir ilações que fortaleçam esclarecimentos à guisa do processo de produção espacial do Nordeste a partir dos projetos de desenvolvimento implantados em seu território. Nesse sentido, 
compreende-se que os referidos autores complementam esse estudo do desenvolvimento regional nordestino e seus reflexos na região Sul do Maranhão.

Há um paralelismo entre as disparidades regionais e as nações que se conformam no conjunto do sistema capitalist, mediante sua lógica de funcionamento nos vários estágios de seu desenvolvimento, respeitando suas peculiaridades regionais (BARRETO; LIMA, 2015). O desenvolvimento industrial de São Paulo começou a definir a divisão regional do trabalho na economia brasileira, ou seja, começou a forjar uma divisão regional do trabalho nacional (OLIVEIRA, 1981).

Assim, para entender o caminho seguido pela região Nordeste, é preciso analisá-la no contexto da formação do centro econômico dominante no país que foi a região Centro-Sul. A análise deve partir do processo originário de acumulação de capital. Portanto, a região Nordeste, a partir das diretrizes desse centro capitalista nacional, começou a assumir um papel nesta divisão do trabalho que passaria a influenciá-la e, concomitantemente, as inter-relações com o restante do país e com o centro econômico dominante. Nesse papel, verifica-se que este ciclo capitalista formado "toma espacialmente a forma de destruição das economias regionais ou das regiões" (OLIVEIRA, 1981, p. 75-76).

O processo de centralização do capital como uma das faces do desequilíbrio, que foi se formando no centro dominante via extração do excedente formado no Nordeste, só poderia levar aos desequilíbrios entre as regiões de maneira que as disparidades são o sinal do movimento diferencial de acumulação nas relações entre as regiões Nordeste e Centro-Sul (OLIVEIRA, 1981).

Partindo do pressuposto que a estrutura fundiária é um ponto fundamental para entender a organização econômica e social nessa região, torna-se necessário buscar elementos históricos da posse da terra na região Nordeste (FURTADO, 2008; ANDRADE, 2006; FAUSTO, 1995; SANCHES, 2008), que determinaram sua estrutura econômica e as relações sociais de produção. Embora essa posse da terra tenha ocorrido na era colonial, ela atendeu antes os estímulos de colonização por meio da doação de grandes extensões de terras (capitanias hereditárias e sesmarias).

No ponto de vista de Carvalho (2008), o período 1960-2000 ficou marcado na economia nordestina pelas taxas positivas de crescimento e progressiva articulação à economia brasileira. As quatro décadas correspondem a etapas distintas desse período: 1960, de expansão; 1970, de continuidade do crescimento; 1980, de desaceleração e 1990, de mais desaceleração e crise.

Com relação ao Maranhão, é importante frisar que, para o IBGE, até meados do século XX esse estado não pertencia ao Nordeste. As terras maranhenses integravam o Meio-Norte. Ao propor a criação da Superintendência do Desenvolvimento do Nordeste (SUDENE), no final da década de 1950, Celso Furtado incluiu esse estado na área de atuação daquele órgão e, consequentemente, o Maranhão passou a integrar o Nordeste. 
Em seu trabalho "Formação Econômica do Brasil", Furtado (2008) reconheceu as especificidades da ocupação maranhense e considerava como dois "sistemas autônomos": o do Pará e o do Maranhão. Sendo este último articulado com a região açucareira por meio da pecuária, enquanto o sistema paraense baseava-se na economia extrativa vegetal. O sistema maranhense, após crise na produção do açúcar e euforia na produção algodoeira, reaparece por meio da Política de Desenvolvimento Econômico para o Nordeste constituindo a base para a criação da SUDENE (GTDN, 1959).

Em função da emigração de nordestinos partindo em direção dessa então fronteira agrícola (o Maranhão), Furtado (2008) propõe o uso das terras úmidas e férteis. O objetivo era que essa fronteira abrigasse uma base agrícola moderna voltada para a produção de alimentos a ser realizada por nordestinos na segunda metade do século XX. Nesse contexto, uma das principais contribuições da análise que Celso Furtado fez ao processo de ocupação humana e econômica do Nordeste e ao entendimento das bases históricas da questão nordestina foi a compreensão da estrutura e da dinâmica do sistema baseado na pecuária, no algodão e na agricultura de subsistência. Assim, segundo o autor, a estrutura socioeconômica do Nordeste semiárido, transformado depois em área de forte emigração, é embrião de crises sociais extremas em momentos de prolongada estiagem (FURTADO, 1989; DE ARAÚJO; SANTOS, 2009).

Desse modo, ao concentrar seus efeitos, sobretudo na agricultura de subsistência, na qual se encontra a maior parte da população, a seca ganha o caráter de catástrofe social e de problema de dimensão nacional, a exemplo do que ocorreu com a forte estiagem de 1877-1879, que trouxe o governo para o centro das atenções (FURTADO, 1989; DE ARAÚJO; SANTOS, 2009). Considera-se que esta é uma das principais contribuições teóricas de Furtado ao entendimento da questão regional brasileira (OLIVEIRA, 1981).

Ao montar o que Oliveira (1981) chama de "modelo de equilíbrio", no qual a sobrevivência dos baixos padrões de produtividade é um mecanismo endógeno de articulação entre a produção de subsistência e a de mercadorias no interior do latifúndio pecuário nordestino, Celso Furtado teria desvendado o segredo da manutenção da arcaica estrutura agrária do Nordeste. Para esse autor, que antes a seca era o problema central do Nordeste, a seca é consequência (e não causa) da questão sertaneja. A causa era a estrutura social e econômica que ali se reproduzia há séculos. E, portanto, era isso que precisava ser transformado (FURTADO, 1989; DE ARAÚJO; SANTOS, 2009). 


\section{Ciclos econômicos e trajetórias migratórias: Imperatriz-MA formação histórica e desenvolvimento}

Vários ciclos de desenvolvimento econômico aconteceram no sudoeste maranhense, mas, para estabelecer um ponto de partida nestas análises, utiliza-se a decadência do período aurífero das minas de Goiás (atualmente estado do Tocantins). Esse é um período importante, onde a produção econômica do Centro-Oeste, no início do século XIX, redirecionou as atividades de extrativismo e criação de gado ao sentido Norte do estado (ABREU, 1998).

Nesse mesmo contexto de decadência e mudança, incluem-se os deslocamentos populacionais registrados no Nordeste provocados pelas secas, mormente no final dos séculos XVIII e XIX e início do XX, originando uma migração de parte da população de Pernambuco, Paraíba, Piauí, Bahia e Ceará em direção aos sertões de Pastos Bons no Maranhão (BRITO,2009).

Em função dessa mudança, as frentes agrícolas e pastoril avançaram no sertão de Pastos Bons prosseguindo até Imperatriz. Os pioneiros, sejam qual for a sua descendência, apresentam traços característicos, como o espírito especulativo das grandes iniciativas e a confiança no futuro para comprar novas terras em vez de investir nas propriedades que possuem. Nessa mesma linha de estabelecimento de conceitos, os geógrafos desde os anos 1940, importaram a designação de zona pioneira referindo-se à frente pioneira (MARTINS, 1997; WAIBEL, 1958).

\section{Os ciclos de desenvolvimento na formação histórica de Imperatriz - MA}

O ciclo da construção da rodovia Belém-Brasília se constituiu e influenciou o surgimento de novos ciclos econômicos e, a partir disso, condicionou a dinâmica dos fluxos migratórios, possibilitando o desenvolvimento econômico de Imperatriz.

A relação entre o transporte e o desenvolvimento regional é uma temática presente nas discussões dos teóricos desenvolvimentistas. Estudos sobre a importância da infraestrutura de transportes no incremento dos fatores na mobilização dos fatores de produção e o efeito no crescimento regional, além do papel dos transportes no desenvolvimento regional, estão presentes nas análises de Becker (1974) e Siebert (1969). O ciclo do arroz destaca-se juntamente com o da madeira em função dessa importante construção rodoviária. As terras maranhenses tiveram sua ocupação na parte sul com a participação de nordestinos e a propagação da boa qualidade das terras na Amazônia. Um registro histórico conhecido desde a exploração da borracha com sua expansão no período de 1879 a 1912 (BENCHIMOL, 1992), a produção e exportação do arroz no século XVIII e a grande produção do algodão da metade desse século para o final do século XIX. 
Abordar o povoamento de Imperatriz a partir da produção do arroz implica esclarecer sobre a formação de um excedente de mão de obra oriundo da decadência da economia castanheira no sudoeste paraense, substituída pela expansão e queda na produção do arroz. Essa dinâmica, que reuniu aquisição de terras devolutas e fluxos migratórios, deixou no final da década de 1970 um grande contingente de pessoas desempregadas (BARROS, 1996).

O ciclo do ouro é representado neste artigo pelo garimpo de Serra Pelada como o marco mais significativo desse período, que apareceu no final do ano de 1979 e foi considerado o maior garimpo a céu aberto do mundo. Os efeitos causados ao município de Imperatriz foram caracterizados pelo esvaziamento durante o auge de Serra Pelada, com a saída das pessoas principalmente da agricultura para a região de extração, transferência de recursos financeiros de empreendimentos para custear o garimpo e o fornecimento de produtos necessários para a sobrevivência dos garimpeiros (COSTA, 1993).

A influência dos fluxos migratórios na formação histórica de Imperatriz pode ser observada com a tabela a seguir.

\section{Tabela 1 - Populações migrantes por lugar de nascimento e sexo - Imperatriz - 1980}

\begin{tabular}{ccccccc}
\hline UF & Total Município & Homem & Mulher & Total Microrregião & Homem & Mulher \\
\hline BA & 6.581 & 3.412 & 3.169 & 6.803 & 3.520 & 3.283 \\
\hline CE & 14.164 & 7.615 & 6.549 & 17.631 & 9.598 & 833 \\
\hline ES & 1.680 & 857 & 823 & 1.748 & 911 & 637 \\
\hline GO & 6.679 & 3.089 & 3.590 & 6.544 & 4.089 & 4.455 \\
\hline MA & $\mathbf{1 3 7 . 8 3 2}$ & $\mathbf{6 9 . 3 7 5}$ & $\mathbf{6 8 . 4 5 7}$ & $\mathbf{1 8 1 . 0 4 3}$ & $\mathbf{9 1 . 4 7 8}$ & $\mathbf{8 9 . 5 6 5}$ \\
\hline MG & 5.986 & 3.173 & 2.813 & 6.220 & 3.508 & 3.112 \\
\hline PA & 2.033 & 1.034 & 999 & 2.309 & 1.173 & 1.136 \\
\hline PB & 2.297 & 2.297 & 1.314 & 2.650 & 1.519 & 1.131 \\
\hline PE & 3.401 & 1.832 & 1.569 & 4.235 & 2.314 & 1.921 \\
\hline PI & 14.930 & 7.819 & 7.111 & 19.142 & 10.086 & 9.056 \\
\hline RN & 1.235 & 676 & 559 & 1.429 & 776 & 653 \\
\hline
\end{tabular}

Fonte: IBGE Censo Demográfico 1980 - Vol 1 Tomo 4 no 7, p.157-185. Organizado pelo autor.

A tabela 1 apresenta uma distribuição dos migrantes conforme lugar de nascimento. Destacam-se os maranhenses, que se utilizaram das estradas (MA 275, MA 280, MA 226, MA 122, BR 226, MA 335, MA 006, MA 375, MA 012, MA 230, BR 010) para acessarem Imperatriz. Os dados numéricos dessa tabela apontam os lugares mais destacados em termos de quantidade de migrantes. Suas trajetórias provenientes desses números são analisadas com base nos relatos das pessoas entrevistadas, conforme os exemplos a seguir. 


\section{Relatos das entrevistas de imigrantes}

Foram realizadas entrevistas estruturadas que permitiram qualificar os dados censitários na medida em que possibilitaram resgatar informes originados por meio relatos dos entrevistados sobre as trajetórias (individuais e coletivas) de quem migrou para Imperatriz em seus diferentes ciclos de desenvolvimento durante o período analisado. As entrevistas contemplaram questões relacionadas ao perfil dos migrantes, aos locais de origem e às condições de trabalho antes do deslocamento, às condições de deslocamento, às condições de chegada e de instalações e às atividades que passaram a desenvolver em Imperatriz. Foram selecionados aleatoriamente para entrevista migrantes entre comerciantes, empresários, políticos, religiosos, trabalhadores com idades (no momento da realização das entrevistas) acima dos 60 anos e que se deslocaram para Imperatriz durante os ciclos do arroz, a construção da rodovia Belém-Brasília, o ciclo da madeira e o do ouro.

As contribuições são exemplificadas conforme relatos a seguir.

a) Eu nasci em Caçapava do Sul, perto de Bagé, quando eu era solteira eu trabalhava com meus pais, de roça no Rio Grande do Sul, depois me casei com um rapaz, que trabalhava em firma de BR e numa época transferiram ele pra cá pra SUTEPA. Isso foi assim de 1955, 1958, e nos trabalhos de BR, ele era sempre um dos primeiros que vinha, ele era chefe essas coisas assim, e aqui era um lugar assim (...) e depois que chegamos aqui, ficamos muito tempo, ele arrumou outra mulher e me deixou aqui criando meus filhos. Não veio ninguém da família de lá pra cá, eles tão tudo aposentado..." (Maria, mulher, 68 anos de idade).

A partir do relato, percebe-se que o casal migrou em função do trabalho de um dos cônjuges, no caso específico, do marido. Vale salientar que a migração das mulheres nem sempre é uma escolha autônoma no processo migratório. $\mathrm{Na}$ maioria das vezes ela é motivada pelo casamento, fato este que também pode ser observado no caso das migrações internas envolvendo determinados ciclos econômicos. O marido deslocou-se para trabalhar na construção da rodovia Belém-Brasília e levou a esposa. A situação de fragilidade da mulher migrante fica evidenciada no relato acima. A partir do momento que o casamento acaba, como nesse caso em particular, a mulher pode se sentir abandonada. No relato fica evidente que a rede familiar é algo importante para o suporte daqueles que migram.

b) "Quando eu cheguei aqui tinha apenas 8 anos de idade, a família do meu padastro morava aqui, aí a gente veio também em 1958 e fui morar na gameleira povoado de João Lisboa. Vi tudo da abertura da estrada Belém-Brasília, os tratores, era uma poeira tão grande que o povo 
chamava os operários de cassacos e candangos. Estudei em João Lisboa fiz uma preparação para o trabalho. Aqui a rua 15 de novembro era a rua do fio porque tinha um fio de telégrafo e a avenida Getúlio Vargas era a rua da piçarra......" (Iolanda/mulher/ 66 anos de idade).

A construção da rodovia Belém-Brasilia, no trecho delimitado para o município de Imperatriz, registra historicamente a abertura da mata, a selva amazônica. Assim, é possível entender que parte dos imigrantes trazidos por esse ciclo para esse município eram trabalhadores recrutados pelas firmas contratadas para essa obra ou tinham vinculações com esses. Os relatos indicam duas histórias de migração motivadas pelo mesmo ciclo econômico, mas com implicações diferenciadas no que diz respeito às redes de apoio familiar: primeiro um operário migrando por imposição do trabalho com implicação no deslocamento da família saindo do Sul do País para a Região Norte. O segundo caso relata uma migração influenciada por parentes já instalados em Imperatriz, sobrevivendo a partir de em uma dinâmica de construção de estrada. No relato da Iolanda há registro do deslocamento da família em 1958, influenciada por outra já residente na microrregião de Imperatriz, indicando, desse modo, como esse ciclo condicionou fluxo migratório nesse período. Seguiu-se a esse ciclo o de exploração da madeira, do qual têm-se os seguintes relatos:

c) "A seca do Ceará era demais, viemos pra fortuna, meu filho caçula tinha seis anos, meu marido era fotógrafo, aqui botei uma roça, comprei a terra barato, tinha uns animais, cheguei a criar cem bois. Naquele tempo tinha muito caminhão levando madeira, e um caminhão chamado folha larga, que levava muita madeira, veio muita gente do Ceará pra cá, uns primo meu e a irmã da minha mãe veio também .... (Anita/mulher/73 anos de idade).

No caso dessa família, as dificuldades econômicas no local de origem, especialmente ligadas às questões ambientais, motivaram a migração, entretanto fica evidente que era comum a migração de muitas famílias que partiam de municípios do Ceará rumo à Imperatriz e a rota de transporte da madeira também refletia a própria rota da migração naquele período. A seca nordestina motivou grande parte das migrações do Nordeste em direção a outros Estados do Brasil, especialmente a Região Sudeste.

d) "Era assim, meu pai e minha mãe morava no Ceará, a gente era tudo pequeninho, nesse tempo não tinha carro ficamo em São Domingo já ouviu falar? Fica lá pra Presidente Dutra, plantamo roça, depois fumo pra Imperatriz, aqui era tudo mato, nós trabalhava lá na serra do doutor Armindo, era oito irmão criava animal, plantava roça (...) Ave Maria, aqui tinha tanto madeireiro, que chegava a fazer poeira, trabalhei no 
garimpo serra pelada até aquele bicho morrer, e depois ficou o Curió..." (José/homem/76 anos de idade).

$\mathrm{Na}$ fala do entrevistado, observa-se que as principais atividades econômicas dos migrantes possuem ligação com os diferentes ciclos econômicos que marcaram a região Sul do Maranhão, especialmente Imperatriz. $\mathrm{O}$ trabalho com a agricultura e o ouro vieram antes do trabalho com a madeira.

e) "Não, eu vim do Povoado do Sítio Novo do Goiás na época, que hoje é Tocantins né, eu tinha acho que 10 anos, tem muitos anos. Transporte, não tinha, não tinha carro, bicicleta, o transporte era os animais, cavalo né, também não existia estrada não, era só caminho né, tinha muito arreião, era muita dificuldade pra se locomover. Eu acho que como é perto de Imperatriz, né, eu acho que no período do dia. Quando cheguei aqui já tinha tias minhas daqui mesmo, né, aliás, parece que ela veio foi lá da Passagem Franca estado do Maranhão e veio direto pra Imperatriz, e eu não sei bem como foi que o papai veio não, provavelmente foram essas pessoas, amigos e parentes. Na época só veio meu pai pra cá, agora de lá da Passagem Franca pro Tocantins vieram toda a família, veio pai, veio a mãe dele, e todos os irmãos, todos vieram pra qui, agora pra cá para Imperatriz veio ele, ele era alfaiate, costurava, aqui era só ele que trabalhava minha mãe ficava em casa e só ele trabalhava, veio aqui pra esse mercado. Quando ele chegou ele veio primeiro, aí aqui ele ficou morando nessa casa da minha tia e ficou trabalhando no mercado. Arrumou um pontinho ali pequeno e começou a trabalhar depois de um tempo e que a gente veio ele vendia mercadoria. A clientela daqui era todinha aqui do Imbiral, Tocantins. A passagem era por aqui, de barco. Era aqui, porque aqui era o centro, era a rua principal a cidade. Eu voltei sim a visitar. A gente sempre ia final de semana feriado mais com o tempo a gente foi deixando de ir estudei aqui em Imperatriz, fiz faculdade, arrumei emprego no Tocantins assim que terminei a faculdade passei no concurso no Tocantins e fui trabalhar la como a estrada era ainda de difícil acesso eu passei a morar lá e às vezes a gente vinha no sábado e voltava no domingo à tardinha..." (Zélia/mulher/67 anos de idade).

O relato acima evidencia as principais dificuldades de mobilidade encontradas durante a migração, especialmente a falta de transportes e estradas para empreender o percurso migratório. As dificuldades de locomoção não impediram as migrações para Imperatriz, mas faziam com que as famílias não migrassem em conjunto, sendo que, muitas vezes, um dos membros, geralmente do sexo masculino, enfrentasse a travessia para, posteriormente, trazer a família ao local de destino. No relato, fica evidente que as redes de solidariedade familiar foram importantes para que o migrante pudesse amenizar os desafios impostos pela migração. Já para a segunda geração, a escolaridade e a qualificação, assim como a 
integração ao local de destino, intensificaram a rotatividade migratória, que pode ser marcada por idas e vindas.

\section{Considerações finais}

Nas discussões edificadas ao longo deste artigo, ressaltou-se que a dinâmica de desenvolvimento de Imperatriz criou necessidades que impulsionaram fluxos migratórios, mas, ao mesmo tempo, esses fluxos estivera vinculados às redes pessoais, interpessoais e espaciais. O município de Imperatriz faz limite com os seguintes municípios do Maranhão: João Lisboa, Davinópolis, Cidelândia, São Francisco do Brejão, Senador Lá Roque e Govenador Edison Lobão. Em função disso, considera-se que grande parte dos vínculos demográficos das trajetórias migratórias tem esses locais como referências pela proximidade, pois as variáveis "distância", "tecnologia" e "condições econômicas" são fatores de influenciam nas migrações (RAVENSTEIN, (1980). Exemplo disso está no relato da entrevistada "ZÉLIA", que fez seu deslocamento migratório transportada por animal (cavalo) em função da curta distância e inexistência de estradas.

Os movimentos migratórios para Imperatriz foram se definindo e se redefinindo observando que eles aconteceram inicialmente tendo Imperatriz como uma passagem destacada pelo porto, ou seja, uma via de acesso para os castanhais de Marabá (PA). Com o fim da exploração da castanha, iniciou-se em Imperatriz o ciclo do arroz que se expande com a rodovia Belém-Brasília, desse modo as configurações do espaço produtivo foram se constituindo, com o migrante dono de uma pequena propriedade; o migrante trabalhador na pequena propriedade e o migrante proprietário dos meios de produção mais importante daquela época (ferramentas, equipamentos, suprimentos e estrutura de comercialização).

A estrutura e superestrutura assumiram formas derivadas da formação econômica do Nordeste, promovendo um crescimento concentrado da riqueza. Assim, este artigo abordou de forma singular as migrações internas na concretização do povoamento do município de Imperatriz, sob a égide do materialismo histórico, valorizando a formação das relações socioeconômicas desse espaço por meio dos distintos atores desse processo migratório.

\section{REFERÊNCIAS}

ABREU, Capistrano de. Capítulos da História Colonial. Ministério da Cultura Fundação Biblioteca Nacional: Departamento Nacional do Livro. Brasília, 1998. 
ALVES, Álvaro M. O método materialista histórico dialético: alguns apontamentos sobre a subjetividade. Revista de Psicologia da UNESP. 9(1), 2010: Disponível em: <http://www2new.assis.unesp.br/index.php/revista/article/viewFile/74/214>. Acesso em: 30 out. 2015.

ANDRADE, Manuel Correia. A Terra e o Homem no Nordeste. 7. ed. São Paulo: Cortez, 2006.

BAENINGER, Rosana. Migrações internas no Brasil no século 21: entre o local e o global. Trabalho apresentado no XVIII Encontro Nacional de Estudos Populacionais, ABEP, realizado em Águas de Lindóia/SP - Brasil, de 19 a 23 de novembro de 2012.

BARRETO Ricardo Candéa Sá; LIMA, Sérgio Ricardo Ribeiro. A região Nordeste: disparidades interestaduais e desigualdade econômica e social, 19601990. Nexos Econômicos, Salvador, v. 9, n. 2, jul./dez. 2015. Disponível em: https://portalseer.ufba.br/index.php/revnexeco/article/download/21681/14049 Acesso em: 17 fev. 2017.

BARROS, Edelvira M. M. História da fundação de Imperatriz. Imperatriz: Ética, 1996.

BENCHIMOL, Samuel. Romanceiro da Batalha da Borracha. Manaus: Imprensa Oficial, 1992.

BECKER, Bertha. A Amazônia na Estrutura Espacial do Brasil. Revista Brasileira Geografia, Ano 36, nº 2, FIBGE - Rio de Janeiro, 1974.

BRITO, Eliseu Pereira de. O papel de Palmas-TO na rede de integração regional. 2009. Dissertação (Mestrado em Geografia) - Faculdade de Ciências Humanas, Universidade Federal da Grande Dourados, Dourados, 2009.

BRITO, Fausto. Brasil, final de século: a transição para um novo padrão migratório? In: Transições Migratórias, IPLANCE, 2002. Disponível em: <www.abep.nepo.unicamp.br/.../2000/.../Brasil,\%20Final\%20de\%20sécul>. Acesso em 10 ago. 2015.

CANO, Wilson. Migrações, desenvolvimento e crise no Brasil. Campinas, IE/UNICAMP. 1996. 
CARVALHO, Cícero P. de O. Sinais de um novo padrão de crescimento (2000/2008). In: Encontro Nacional de Economia, 36. 2008, Salvador. Anais. Salvador: ANPEC, 2008.

COSTA, Francisco de A. Nem tudo no ouro reluz: considerações para uma economia política da garimpagem na fronteira amazônica. In: MHATIS, Armin; REHAAG, Regine (Orgs.). Consequência da garimpagem no âmbito social e ambiental da Amazônia. Belém: BUNTSIFAT/FASE/KATALYSE, 1993.

DE ARAÚJO, Tania B. de; SANTOS, Valdeci Monteiro dos. Desigualdades regionais e nordeste em formação econômica do Brasil. 2009. Disponível em: <http://www.ipea.gov.br/agencia/images/stories/PDFs/livros/14_cap07_Tania _Valdeci.pdf $>$.

DE HAAS, Hein. Migration and development: a theoretical perspective. International Migration Review, New York, v. 44, n. 1, p. 227-264, 2010.

DUHRAM, E. A caminho da cidade: A vida rural e a migração para São Paulo. São Paulo: Perspectiva, 1973.

FARIA, Vilmar. Desenvolvimento, urbanização e mudanças na estrutura do emprego: a experiência brasileira dos últimos trinta anos. In: SORJ, B., ALMEIDA, M. (Orgs.). Sociedade e política no Brasil pós- 64. São Paulo: Brasiliense, $1983 . \quad$ Disponível em: <http://www.abep.nepo.unicamp.br/docs/rev_inf/vol19_n1_2002/vol19_n1_20 02_3artigo_49_74.pdf $>$. Acesso em: 17 jun. 2016.

FAUSTO, Boris. História do Brasil. 14. ed. São Paulo: Edusp, 1995.

FAZITO, Dimitri. Análises de redes sociais e a migração: mito e realidade. XIII Encontro da Associação Brasileira de Estudos Populacionais. Ouro PretoMG, 2002. Disponível em: <www.abep.nepo.unicamp.br/docs/anais/pdf/2002/gt_mig_st1_fazito_texto.pdf >. Acesso em: 23 dez. 2016

FURTADO, C. O Nordeste: reflexões sobre uma política alternativa de desenvolvimento. Revista de Economia Política, São Paulo, v. 4, n. 3, p. 5-14, jul./set. 1984.

FURTADO, C. A Fantasia Desfeita. São Paulo: Paz e Terra, 1989.

FURTADO, C. Formação Econômica do Brasil. 34. ed. São Paulo: Companhia de Letras, 2008. 
FUSCO, W. Capital cordial: a reciprocidade entre os imigrantes brasileiros nos Estados Unidos. 2005. Tese (Doutorado em Demografia) - Instituto de Filosofia e Ciências Humanas, Universidade Estadual de Campinas, Campinas, 2005.

IBGE. Censo Demográfico Recenseamentos gerais Brasil - 1960, 1970, 1980. Disponível na Delegacia de Estatística/IBGE São Luís-MA. CD vol I tomo III $1^{\text {a }}$ parte, p. 87-88, 1960/Maranhão e Piauí. Acesso em: 29 out. 2016.

LEE, Everett S. Uma teoria sobre a migração. In: MOURA, Hélio (Coord.). Migração Interna, Textos Selecionados, tomo I. Fortaleza: Banco do Nordeste, p. 89-114, 1980.

LIMA, João Policarpo R. Fronteiras agrícolas no Brasil: a lógica de sua ocupação recente. Nova Economia, Belo Horizonte, v. 10, no 01, jul. 2000. Disponível em: <revistas.face.ufmg.br/index.php/novaeconomia/article/download/2145/1123>. Acesso em: 02 mar. 2017.

LIMA Sérgio Ricardo Ribeiro. A região Nordeste: disparidades interestaduais e desigualdade econômica e social, 1960-1990. Nexos Econômicos, Salvador, v. 9, n. 2, jul-dez. 2015. Disponível em: https://portalseer.ufba.br/index.php/revnexeco/article/download/21681/14049 Acesso em: 17 fev. 2017.

MARX, Karl. Contribuição à crítica da economia política. São Paulo: Martins Fontes, 2006.

MARX, Karl; ENGELS, Friedrich. Obras escolhidas. VII. São Paulo: AlfaOmega 2006.

MARTINS, José de Souza. Fronteira: a degradação do outro nos confins do humano. Hucitec. São Paulo, 1997.

MATOS, Ralfo Edmundo da Silva; BRAGA, F. G. Redes Sociais, Redes Territóriais e Migração. In: XIV Encontro Nacional de Estudos Populacionais, 2004, Caxambu. Anais do XIV Encontro Nacional de Estudos Populacionais. Campinas: ABEP, 2004.

MATOS, Ralfo Edmundo da Silva; BAENINGER, Rosana. Migration and Urbanization in Brazil: Processes of Spatial Concentration and Deconcentration and the Recent Debate. Anais XXIV General Population Conference, 2001, Salvador. Brasília Demography. Associação Brasileira de Estudos Populacionais, 2001. 
OLIVEIRA, Antônio T. R. de. Reflexões sobre os deslocamentos populacionais no Brasil. Rio de Janeiro: IBGE, 2011. Disponível em: <https://www.ibge.gov.br/estatisticas/sociais/populacao/9159-reflexoes-sobreos-deslocamentos-populacionais-no-brasil.html>. Acesso em: 16 jul. 2016.

OLIVEIRA, Francisco de. Elegia para uma região: Sudene, Nordeste. Planejamento e conflitos de classes. Rio de Janeiro: Paz e Terra, 1981.

OLIVEIRA, O.; GARCIA, B.; STERN, C. Notas sobre a teoria da migração interna: aspectos sociológicos. In: MOURA, H. M. (Coord.). Migrações internas: textos selecionados. Fortaleza: BNB/ETENE, 1983.

RAMELLA, Franco. Por un uso fuerte del concepto de red en los estudios migratorios. In: BJERG, María; OTERO, Hernán (Orgs.). Inmigracion y redes sociales en la Argentina moderna. Tandil: CEMLA-IEHS, p. 9-21, 1995.

RAVENSTEIN, E. G. “As leis da migração”. Nações Unidas - Conceitos básicos, definições e mensuração da migração interna. In: MOURA, Hélio A. de Migração Interna: textos escolhidos. Fortaleza: BNB/ETENE, p. 19-88, 1980.

SANCHES, Almir Teubl. A questão de terras no início da República: o registro Torrens e sua aplicação. Dissertação (Mestrado em Teoria Geral e Filosofia do Direito). 2008, 182 f. Faculdade de Direito - Universidade de São Paulo, São Paulo, 2008.

SIEBERT, Horst. Regional economic growth: theory and policy. International Textbook Co., 1969.

SIMMONS, A. B. Explicando la migración: la teoria em la encrucijada. Estúdios demográficos y urbanos, México: Colégio de México, v. 6, n. 1, p. 5-31, 1991. Disponível em: <biblioteca.ibge.gov.br/visualizacao/livros/liv49781.pdf>. Acesso em: 05 aug. 2016.

SINGER, Paul, Migrações internas: considerações teóricas sobre o seu estudo. In: MOURA, Hélio (Coord.). Migração Interna, Textos Selecionados, tomo I. Fortaleza: Banco do Nordeste, 1980.

SOARES, Weber. Da metáfora a substância: Redes Sociais, Redes Migratórias e Migração nacional e internacional em Valadares e Ipatinga. 2002. Tese (Doutorado em Demografia) - Centro de Desenvolvimento e Planejamento Regional, Universidade Federal de Minas Gerais, Belo Horizonte, 2002. 
SOUZA, Amauri. Migração, expectativas crescentes e a promessa do protesto coletivo. In: CEDEPLAR, Migrações externas e desenvolvimento regional, Belo Horizonte: Cedeplar, 1973.

TRUZZI, Osvaldo. Redes em processos migratórios. Tempo Social, Revista de Sociologia da USP, v. 20, n. 1, 2006. Disponível em: <http://www.scielo.br/pdf/ts/v20n1/a10v20n1.pdf> Acesso em: 01 jun. 2015.

WAIBEL, Leo. Capítulos de geografia tropical e do Brasil. Rio de Janeiro: IBGE, 1958.

Endereço para correspondência:

Edgar Oliveira Santos - edgar1281948@yahoo.com.br Rua Godofredo Viana, 1300, Centro 65.901-480 Imperatriz/MA, Brasil

EdneyLoiola-edneyloiola@uol.com.br

Rua Godofredo Viana, 1300, Centro

65.901-480 Imperatriz/MA, Brasil

Sônia OliveiraSantos-sonia_7oliveira@hotmail.com Cidade Universitária Paulo VI, s/n, Bairro Balsas 65.055-310 São Luís/MA, Brasil

Rafael de OliveiraAraújo-rafa1593@yahoo.com.br Cidade Universitária Paulo VI, s/n, Bairro Balsas 65.055-310 São Luís/MA, Brasil

Antônio Pereira Lucena - proflucenaneto@hotmail.com Rua Godofredo Viana, 1300, Centro 65.901-480 Imperatriz/MA, Brasil 